\title{
Using Content and Process Scaffolds to Support Collaborative Discourse in Asynchronous Learning Networks
}

\author{
Wong-Bushby, I. \\ NJIT \\ iw2@njit.edu \\ Passerini, K. \\ NJIT \\ pkatia@gwu.edu
}

\author{
Hiltz, S.R. \\ NJIT \\ hiltz@njit.edu \\ Rotter, N. \\ NJIT \\ rotter@njit.edu
}

\author{
Bieber, M. \\ NJIT \\ bieber@homer.njit.edu \\ Swan, K. \\ Kent State University \\ kswan@kent.edu
}

\begin{abstract}
Discourse, a form of collaborative learning [44], is one of the most widely used methods of teaching and learning in the online environment. Particularly in large courses, discourse needs to be "structured" to be effective. This in-progress study investigates how to "scaffold" asynchronous discourse based on the Asynchronous Learning Networks Cognitive Discourse Model (ALNCDM). The ALNCDM is an adaptation of Clark and Brennan's [5] grounding in communications principles within a technology- mediated learning (TML) environment. The model applies content and process scaffolding based on pedagogic principles. The study is a $2 \quad X \quad 2$ design measuring learning effectiveness. Results of a pilot study are described. A major contribution of the study is building and testing a technologymediated, discourse- centered, teaching and learning model called the ALNCDM.
\end{abstract}

\section{Introduction}

Asynchronous Learning Networks (ALN) are "teaching and learning environment(s) located within a Computer-Mediated Communication (CMC) system designed for anytime/anyplace use..." [16]. ALN emphasize substantial studentstudent as well as instructor-student discourse. Discourse, a form of student-student learning, is based on socio-cultural learning theories [44] that knowledge, while realized via an internal mental process, is constructed through social interaction. In particular, according to this school of thought, the use of scaffolding is crucial to guide the learner from his/her actual development level to the potential development level. This gap between the actual and potential development level is called the Zone of Proximal Development [44]. Scaffolding is defined as providing support for the learner at his/her current level of learning until the support is no longer needed. The purpose of scaffolding is to engage the learner through reduced task complexity which in turn lowers learner frustration.

While the most common sources of scaffolding remain instructors and peers, the use of resources such as content and procedural aids constitute other forms of scaffolding. In ALNs, where class sizes tend to be large, the use of noninstructor scaffolds that enable self-regulation [31] is particularly important.

This study investigates how to scaffold asynchronous discourse for the purpose of teaching and learning based on the Asynchronous Learning Networks Cognitive Discourse Model (ALNCDM). The model is an adaptation of Clark and Brennan's [5] principles on effective grounding in communications as two types of scaffolding: content scaffold and process scaffold. The purpose of the content scaffold is to provide external knowledge representation to facilitate assimilation of information in the learner's internal knowledge representation [20]. The purpose of the process scaffold is to reduce task complexity, especially task management activities, so the learner is able to spend more time on tasks directly related to learning. 
Although there have been studies on discourse based on conversation patterns such as the starter-wrapper method [15], and mandates such as required number of contributions per week [42], these studies have not successfully engaged students beyond satisfying the minimal mandated requirement. To fully engage students, this study suggests that when students are prepared [11] and are led to elaborate progressively on the knowledge structure [29], students will feel more self-assured and hence more motivated to engage in the learning activity. This increase in motivation is based on the Expectancy construct [32] which suggests that students will persist in a learning activity that is not too complex or difficult.

The study is a 2 X 2 design manipulated on the two types of scaffolding. Learning effectiveness is measured on two levels: cognitive and affective outcomes. These represent two out of three learning outcomes (i.e., cognitive, affective and psychomotor [28]) that are applicable. In addition, to control for test-anxiety bias [16], cognitive outcomes are assessed using a multi-method approach including test grades, essays and participation.

\section{Theoretical Framework}

\subsection{Technology-mediated Learning Environments}

While the advantage of being anytime/anyplace is one of the most cited benefits, ALNs are not without limitations. One of the most significant drawbacks of ALNs is medium leanness [6]. Medium leanness is the lack of a medium's ability to provide immediate feedback (immediacy), variety of types of cues (text, voice, body language, etc.), personal focus and language variety (number of linguistic symbols). According to Daft and Lengel, textbased media are a lean media (vs. voice or video).

Therefore, in order for an ALN to be effective as a TML environment, what does it have to offer to overcome medium leanness? The answer can be found in the following CMC theories/ principles:

a) Media Synchronicity Theory [8]: the information processing capabilities of a medium can be as important as media richness. In particular, information overload reduction (e.g., threaded-discussion boards) and cognitive processing aids (e.g., technology-mediated concept structures) are especially important under the cognitive pedagogies (e.g., constructivist [12] and socio-cultural learning theories [44]).

b) Asynchronous CMC is reflective: Research [42] has supported the nature of asynchronous communications as more reflective (manifested in longer, more elaborate and content-related messages) than synchronous communications. This inherent ALN feature can be leveraged to enhance deeper cognitive processing.

c) $\mathrm{CMC}$ can be interpersonal: Walther [45] observed that $\mathrm{CMC}$ can be just as effective as face-to-face, provided the groups have an established history of working together and can expect to do so in the future. This implies ALN's suitability to socio-cultural learning approaches for teaching and learning, provided the groups are cohesive.

\subsection{Grounding in Communications}

Collaborative learning involves interpersonal processes as students work together on learning activities [17]. In collaborative learning, the students engage each other to negotiate different perspectives and to reconstruct knowledge [43]. While these statements describe collaborative learning, they describe a more fundamental process called communications.

In a seminal work, Clark and Brennan [5] suggested that to succeed in communications, the parties have to coordinate both the "content" and "process" of what they are doing. For example, two pianists playing a duet need to coordinate the content (e.g., Mozart) as well as the process (entry, exit, pace etc.) of playing. The common denominator is the establishment of a "common ground", or shared meaning, through a process called "grounding". Grounding is described as the moment to moment update of shared meaning on both the content and process dimensions of communications.

With Clark and Brennan's Grounding in Communication principles as backdrop, the next two sections present pedagogical theories that will constitute a theoretical framework for scaffolding discourse. The theoretical framework, the ALN Cognitive Discourse Model, is the topic of section 3.

\subsection{Content Scaffold}

In a recent article, Jonassen [20] states that "problem representation is the key to problem solving among novice learners as well as 
experts." He further elaborates on the importance of problem representation by saying: "instruction must help learners to construct problem representations that integrate their problem representations with domain knowledge." This paper discusses two types of knowledge representations for the purpose of content scaffolding: a static knowledge representation called the concept structure; and a progression of concept structures based on the Vee-heuristic for progressive elaboration of concepts.

Shavelson and Ruiz-Primo [37] define a (static) concept structure as "a hypothetical construct referring to the organization of the relationships of concepts". The main formats for the representation of concept structure are: content structure $[10,25]$, matrix or cross classification table [21], concept map [28], and networking $[18,34]$. Of particular interest to this study is the matrix which is based on Minsky's [26] frame theory. A frame represents categories of information that organizes the content of the subject matter. For example, if the subject matter is "parties", an organizing frame(work) might be "date, place, attendees and menu". A matrix is an extension of frame theory and consists of rows of frame instances. Schwartz [36] has found that matrix representations were substantially superior to text groupings and graphs for certain learning objectives (e.g. comparison/analysis) because they clearly define the needed information.

In addition to static knowledge representations, Novak and Gowin [29] suggest a progression of knowledge representations, called the Vee-Heuristic, for successive elaboration of concepts. The need for successive unfolding of concepts is based on Ausubel's Assimilation theory [1]. Figure 1 illustrates the Vee-Heuristic.

The Vee-heuristic is driven by a series of "Focus Questions" that guides the metacognitive process. The heuristic begins at the bottom of the Vee- the "Record of Events"- and progresses to the top of the Vee- the "Value Claims". On the left side of the Vee, the knowledge structure is unfolded from the atomic to the collective whole (i.e. world view). The left side of the Vee is referred to as the "thinking" or "conceptual" side. On the right side of the Vee, the methods for creating knowledge are introduced. The right side is referred to as the "doing" or the "methodological" side. There is a continuous interplay between the "doing" and "thinking" sides For example 1 , in reading an article (i.e. "record of events"), the learner encounters the "concepts" (or terms). By applying "constraints" to the article, a list of significant source statements may be used to focus attention on the underlying "principles". Next, the significant source statements may be "transformed" into logical groupings, which presents the underlying "theory". The students then compile a group report making explicit the significant theories. These significant findings are the answers or "knowledge claims" to the "focus questions" at the top of the Vee. To complete the Vee-heuristic, the "knowledge claims" should be useful and valuable to the learner. The value to the learner is stated explicitly in the Vee as "value claims".

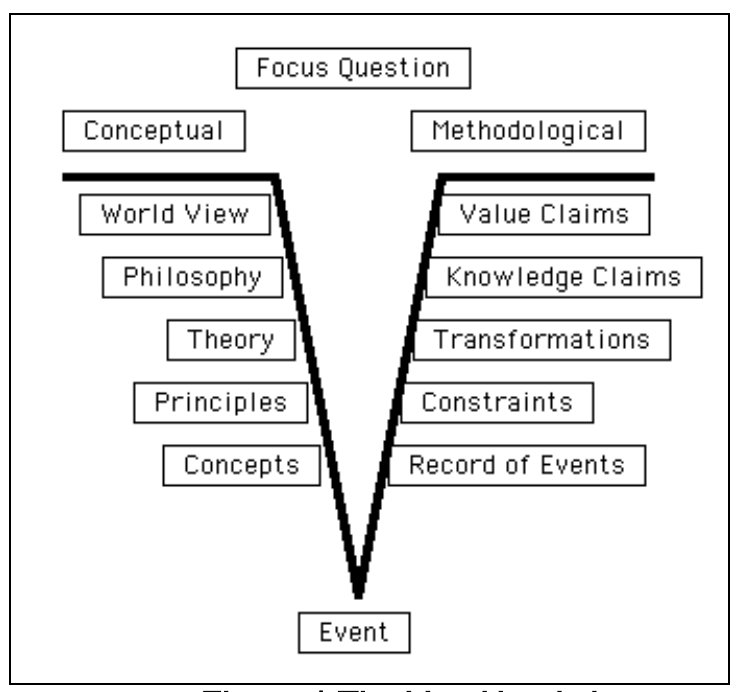

Figure 1 The Vee-Heuristic

\subsection{Process Scaffold}

The second dimension of effective communications is grounding the process in communications. This paper distinguishes between two dimensions of process grounding: a) grounding the sequence of events, and b) grounding the texture of events. To perform an intuitive check on this separation, let us return to the example of the Mozart duet. The players not only have to communicate on when to begin, pause and end the piece (i.e. the sequence of events); but they also need to communicate on the tempo, the tone, the cadence etc. of the piece

\footnotetext{
${ }^{1}$ The example is an adaptation of the Veeheuristic for non-scientific inquiries. Dr. Novak (personal communications 2003) has reviewed the adaptation.
} 
(i.e. the texture of events). Similarly, in order for discourse to be effective, it needs to be structured in these two dimensions as well.

Specifically, one sequence of events is Gagne's Nine Events of Instructions [11]. Gagne introduced the Nine Events of Instruction as a methodology to provide for the conditions of learning. He believes that these events of instruction activate mental processes needed for learning. The Nine Events of Instruction are: gain attention, inform learner of objectives, stimulate recall of prior learning, present stimulus material, provide learner guidance, elicit performance, provide feedback, assess performance and enhance retention and transfer.

Another sequence of events is Gunawardena, Lowe and Anderson's [13] Critical Thinking Model. The Critical Thinking Model is a fivephase model that consists of: sharing/comparing knowledge, discover/explore disagreements, synthesis via negotiated meaning, testing/modifying synthesized meaning, and proof of cognitive change of knowledge. Although it has not been empirically validated, the Critical Thinking Model is a potential group discourse process structure that can provide rhythm/punctuation to discourse, and transition/morph the discourse to deeper levels of cognitive processing.

In addition to the discourse sequence, another dimension in "grounding the discourse process" is the qualitative aspect of discourse referred to as discourse texture. The purpose of discourse texture is to identify best practices that should constitute a backdrop, or pre-requisite environment, for ALN discourse. Based on a survey by the first author of 22 ALN discourse studies [47], three best practices stand out: a) the use of evidence-based discourse [33, 22, 3, 42, $39], b)$ the use of argument-based discourse [30,
$19,42,7]$, and c) the use of in situ leadership roles $[15,42,46,38]$.

\section{The ALN Cognitive Discourse Model (ALNCDM)}

Adapting Clark and Brennan's principles on effective grounding in communications within a TML environment, this paper suggests that ALN collaborative discourse is more effective when it is scaffolded along two dimensions: a) that the content of discourse be scaffolded by a technology-mediated concept structure unfolded via a Vee-heuristic [29] sequence, and b) that the discourse process be scaffolded by an overall technology-mediated process structure following Gagne's Nine Events of Instruction punctuated by "discourse triggers" that transitions/morphs the discourse to conclusion. The underlying discourse texture is evidence-based (versus argumentation based) with assigned in situ leadership roles (facilitator, report writer and weaver). The use of evidence-based discourse places (and limits) the discourse model for learning objectives within the Application level of Bloom's taxonomy [4]. Presumably, for higher levels of cognitive goals in Bloom's taxonomy (such as Evaluation), argumentationbased discourse may be more effective. However, argumentation-based discourse is only effective if certain conditions are met: one of which is the students must have sufficient knowledge [7] of the subject matter. This model is called the ALN Cognitive Discourse Model (ALNCDM) and is depicted in Figure 2. (Note 1: The ALNCDM is applicable for conceptual learning at the Application level of Bloom's taxonomy [4]. Note 2: The ALNCDM refers to discourse as an organizing framework for sensemaking versus discourse as an atomic speech act.).

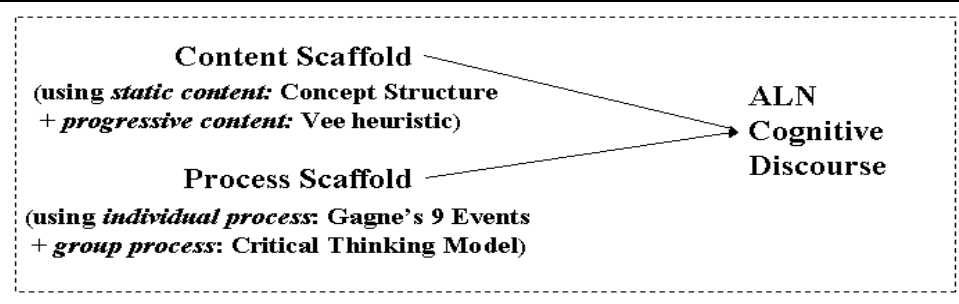

Discourse Texture: Evidence-based (individual cognition)

In situ leadership roles (self-regulated)

*Both Content and Process scaffolds are technology-mediated.

Figure 2 The ALN Cognitive Discourse Model (ALNCDM) 


\section{Content Scaffold}

More specifically, the content needs to be scaffolded by a technology-mediated concept structure that is unfolded in a meta-cognitive sequence based on the Vee-heuristic [29]. This sequence of unfolding (i.e., progression of content) begins with the full text version of an article (the record of events) which progresses through progressive elaborations from significant source statements (constraining the record of events) to the final learning artifact (i.e., (static) concept structure) transforming the record of events into a conceptual framework.

\section{Process Scaffold}

In parallel, the discourse process is scaffolded at two levels: at the micro/individual level and at the macro/group level.

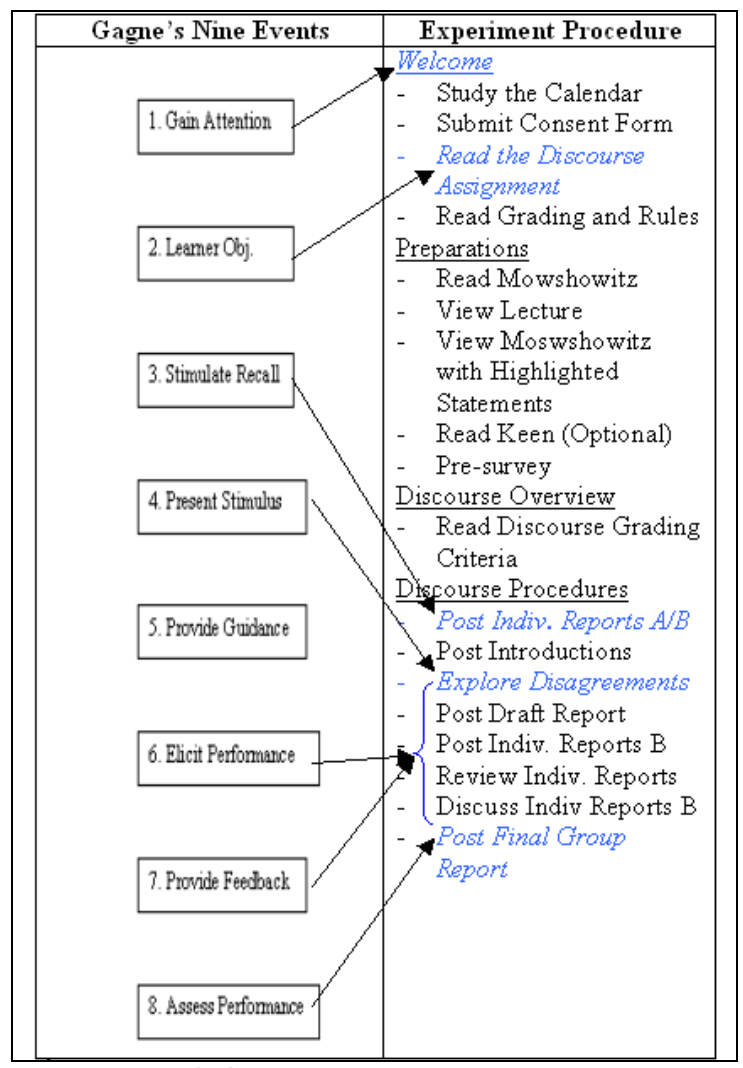

Figure 3 Gagne Nine Events

At the individual process level, each student is required to follow eight of Gagne's Nine Events of Instruction. Figure 3 illustrates how this sequence is operationalized in one of the treatment conditions. Although not explicit from the procedures, "guidance" is operationalized through the use of evidence-based discourse. This is a subtle form of guidance as it requires the student to refer to the source material repeatedly. Repeated reference to the source material is expected to increase assimilation of accurate information. The ninth event, "enhance retention and transfer", is not operationalized because of practical limitations to the length of the experiment.

At the group process level, the discourse progresses through a series of "discourse triggers" based on a five-phase technologymediated group process structure following Gunawardena's Critical Thinking Model. The hypothesis is that each phase of the Critical Thinking Model takes the discourse to deeper levels of cognitive processing, which results in increased learning effectiveness.

These two dimensions of grounding communications form the two manipulated variables of a field study that is underway. The full research approach is depicted in Figure 3.

\section{Research Approach}

The ALNCDM predicts that when discourse is scaffolded along the two dimensions of content and process, then learning effectiveness is higher. In this study, learning effectiveness is operationalized on two dimensions: a) cognitive outcomes (i.e., test grades, amount of quality evidence in group report, amount of task-related discourse interactivity ${ }^{2}$ ), and b) affective outcomes (i.e., satisfaction with group report, discourse and the learning artifact). This represents two of the three learning outcomes (i.e. cognitive, affective and psychomotor [28]) that are applicable. The assessment strategy is multi-method including test grades, essays (i.e., group report), and participation (i.e. discourse interactivity) which should control for testanxiety bias.

Besides learning effectiveness, the research approach includes a motivation measure operationalized in a self-efficacy scale. Selfefficacy is self-perception of one's ability to complete the assignment successfully. This is listed separately from learning effectiveness on a specific learning objective because of its motivational nature. Increase in self-efficacy measures a more lasting accomplishment. It

\footnotetext{
${ }^{2}$ While interactive indicators are one of the 'social indicators' in Swan's schema, it is applied here as an operational indicator of the presence of co-construction of knowledge, that is a cognitive participation indicator.
} 
influences the student's ability to succeed in future learning objectives and represents a higher learning outcome. In addition, two intervening variables are included in the research approach, learning approach [35] and group involvement [24]. In an assignment that requires comprehension, students with a synthesisanalysis learning approach may perform with an advantage. Groups with sound "social space" (characterized by more affective work relationships, stronger group cohesiveness, trust, respect and belonging, satisfaction and a stronger sense of community) may perform better than groups that do not.

Therefore, the overall hypotheses under this research approach are (see Figure 4): a) Since content scaffold is expected to facilitate assimilation of information, learning effectiveness (i.e., test grade (H1a), group report (H2a), interactivity (H3a), satisfaction with group report $(\mathrm{H} 4 \mathrm{a}) /$ discourse (H5a)/ learning artifact (H6)) and self-efficacy (H7a) are higher with content scaffold than without content scaffold.

b) Since process scaffold is expected to increase time on tasks directly related to learning, learning effectiveness (i.e., test grade $(\mathrm{H} 1 b)$, group report $(\mathrm{H} 2 \mathrm{~b})$, interactivity $(\mathrm{H} 3 \mathrm{~b})$, satisfaction with group report $(\mathrm{H} 4 \mathrm{~b}) /$ discourse (H5b)) and self-efficacy (H7b) are higher with process scaffold than without process scaffold.

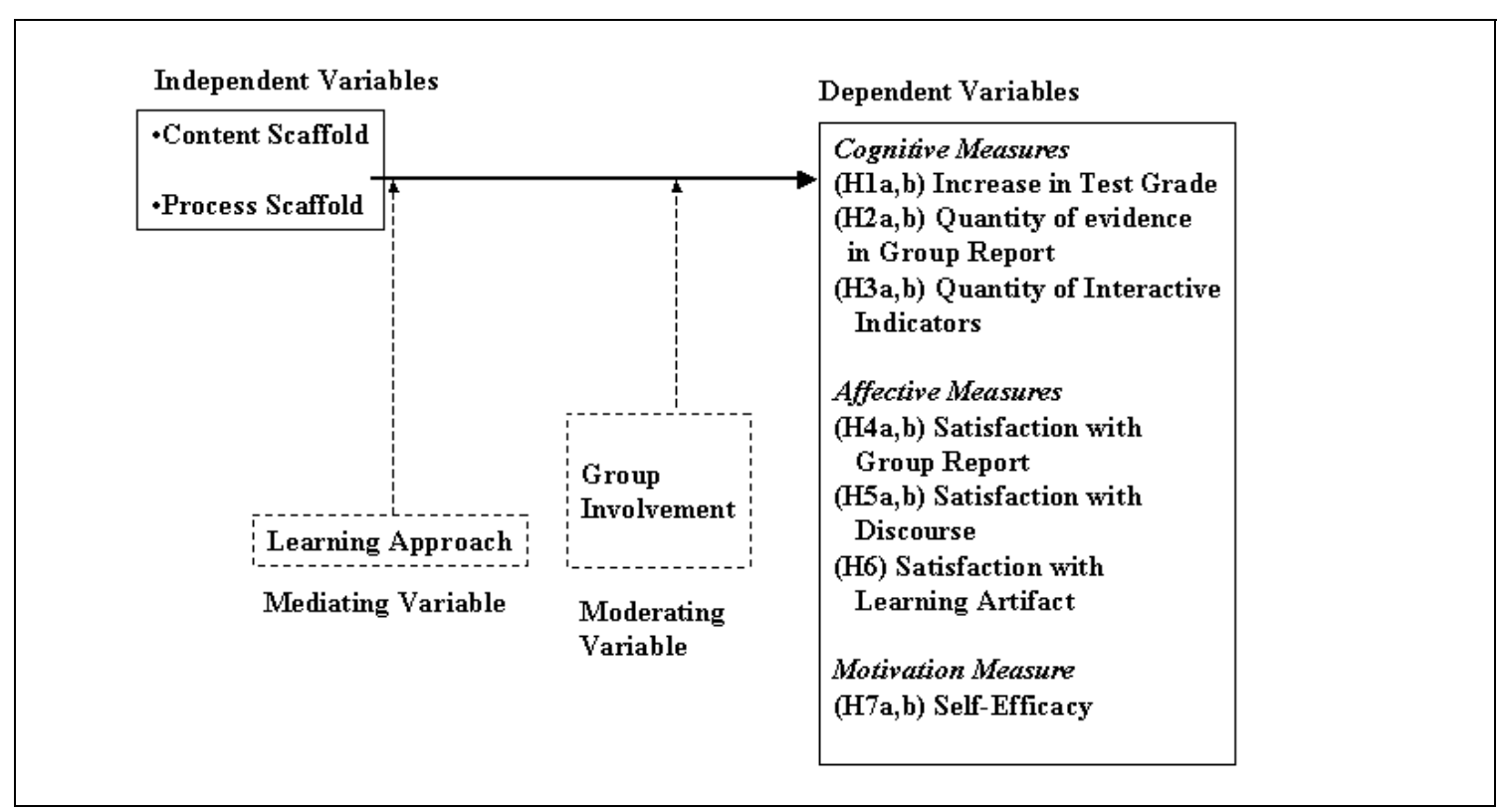

Figure 4 The Research Approach

\section{Research Method}

\subsection{Field Experiment Design}

Table 1 Field Experiment Design

\begin{tabular}{|c|l|l|}
\hline & CS $=$ No & CS $=$ Yes \\
\hline PS $=$ & Ned & White \\
No & Red & \\
\hline PS $=$ & & Orange \\
Yes & Blue & \\
\hline
\end{tabular}

Key:

CS: Content Scaffold

PS: Process Scaffold
To validate the research approach, a field experiment with pre and posttest design is employed. The field experiment is a between group design (each participant in the research is in one and only one condition) with four cells (2 $\mathrm{X} 2$ design). Each cell will have twelve groups and each group will have two to three undergraduate/graduate students. Computer Information Systems (CIS) graduate/ undergraduate students and Management Information Systems (MIS) graduate students will be used for the study, drawn from the courses in which the subject matter of the experiment is appropriate for the syllabus. The students will be randomly assigned to one of the four conditions, with the teams in each condition 
described by a color in order to simplify instructions and discussion of these conditions.

\subsection{The Task}

The participants will read the Mowshowitz [27] article on theoretical perspectives and view the corresponding lecture slides individually prior to discourse. Mowshowitz is an abstract and complex article which discusses five social computing philosophies (aka Mowshowitz Framework): Technicism, Progressive Individualism, Elitism, Pluralism and Radical Criticism. It is selected for the study because it is a concept piece that students have found challenging and therefore in need of a supplemental learning activity as well scaffolding. Afterwards in small discourse groups, they will be asked to discuss and apply the Mowshowitz Framework against a second article (Keen [23]) by classifying it as an example of one of the Mowshowitz philosophies. While Keen discusses several aspects of IT implementation issues (some of which are outside of the Mowshowitz Framework), the students are directed to six source statements at the end of Keen, which describes an IT implementation strategy. These six source statements exemplify one Mowshowitz philosophy: Elitism. A final group report is compiled to summarize the discourse.

\subsection{Experimental Procedures}

The field experiment will be conducted in five phases:

1. Welcome (Day 1): Participants will be provided with a description of the task, grading criteria and rules. After reviewing this material, they will submit a Consent Form granting consent for the study, or requesting an alternate assignment.

2. Preparations (Days $2-4$ ): Participants will be provided with the Mowshowitz article and lecture slides (includes Mowshowitz Framework and the six Keen statements) prior to discourse. They will review the material individually and take a pre-survey, which includes a pre-test.

3. Discourse (Days 5 - 14): Afterwards in small discourse groups, they will discuss and apply the Mowshowitz Framework against a comparative article (Keen) by classifying it as an example of one of the Mowshowitz philosophies. The White and Orange conditions will receive a matrix concept structure (i.e., content scaffold) summarizing the Mowshowitz Framework in a
Microsoft Word matrix. Each of the four conditions will receive a set of discourse procedures (i.e., process scaffold) specific to the condition. A final group report is compiled to summarize the discourse in all conditions.

4. Wrap Up (Day 15): At the conclusion of discourse, the participants will take a post-survey which includes a posttest.

5. Debriefing (Day 16): After the post-survey has been received, a Debriefing document will be provided explaining the purpose of the research and conditions of the study.

\section{Pilot Results and Next Steps}

Six pilot studies were completed between Summer 2003 and Spring 2004. In total, 97 CIS undergraduate, 24 CIS graduate and 14 MIS graduate students participated in the pilots. After these pilots, several changes were made to the field experiment:

- PC Literacy Issue: The first three pilots were conducted using specialized software that required installation on student home computers, as well as subsequent software training. This proved to be a daunting task, particularly for the undergraduates, and manifested in a 50\% drop out rate. Since moving to a Microsoft Word implementation of the content scaffold, the undergraduate drop out rate has decreased to under $20 \%$ in the last pilot. (Ultimately, participation in the study is voluntary.)

- $\quad 2$ X 2 Design Evolution: The first four pilots were conducted based on a 2 (absence/presence of content scaffold) X 1 design. In this version of the experiment, the process scaffold was present in all conditions. In the current version of the experiment, process scaffold was operationalized as a second manipulated variable as it was felt that the 2 X 2 design more accurately reflects the two dimensions of "grounding" in communications.

- Instruments/Scales Evolution: Confirmatory factor analysis and Cronbach's alpha on the first set of instruments selected for "Learning Approach" and "Group Development" were unsuccessful. These included Index of Learning Style [9] and Group Development scale [14]. These have been replaced with the Inventory of Learning Process [35] and Social Space and Social Presence Scale [24]. Both scales have been validated and are expected to have more discriminant and internal validity.

While the pilot data are still being analyzed, Affective Outcomes on three conditions have been analyzed and are shown in Figure 5. (Data 
for the Blue condition are not available from the pilots).

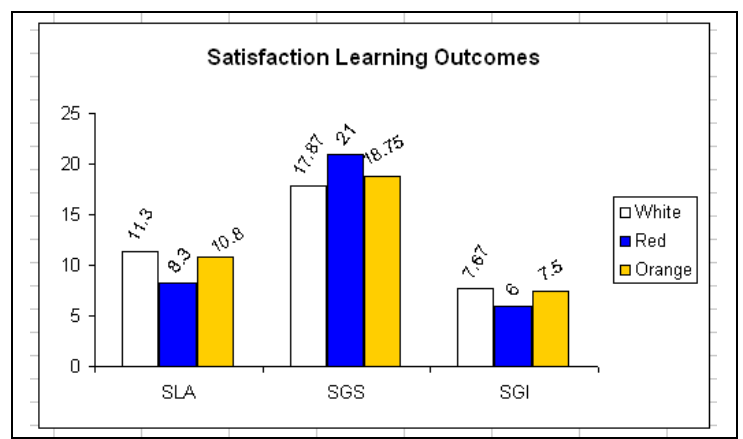

Key:

Figure 5 Affective Learning Outcomes

White: no content scaffold + no process scaffold

Red: content scaffold + no process scaffold

Orange: content scaffold + process scaffold

SLA: Satisfaction with Learning Artifact

(Highest 1 .. 5 Lowest)

SGS: Satisfaction with Group Solution (Lowest

1 .. 5 Highest)

SGI: Satisfaction with Group Discourse

(Highest 1 .. 5 Lowest)

Preliminary results from the last two pilots, with 24 CIS undergraduates in 8 groups and 14 MIS graduates in 4 groups, indicate that Satisfaction with Learning Artifact $(\mathrm{F}=0.48, \mathrm{df}=$ $2, \mathrm{p}=0.6)$, Satisfaction with Group Solution $(\mathrm{F}=$ $2.97, \mathrm{df}=2, \mathrm{p}=0.1)$ and Satisfaction with Group Discourse $(\mathrm{F}=1.17, \mathrm{df}=2, \mathrm{p}=0.4)$ may be highest in the Red condition, next highest in the Orange condition, and lowest in the White condition. This suggests that the use of content scaffold is effective either with or without process scaffold. Moreover, it suggests that content scaffold is most effective without process scaffold. One explanation for the latter is the increase in cognitive load in the Orange condition to study/execute both content and process scaffolds (versus only the content scaffold in the Red condition). According to Cognitive Load Theory [41], additional cognitive load upon a constant working memory increases mental effort. Consequently, satisfaction in the Orange condition may be lower because of increased mental effort. While these preliminary results suggest that the Red condition may be more effective than the White/Orange conditions, it should also be noted that the Red condition has the highest Synthesis-Analysis Learning Approach (White $=47.02$, Red $=52.44$, Orange $=51.86$ ). It is possible that students with a predisposition to synthesis-analysis derive more satisfaction out of the learning artifact, the discourse and the group report. It should also be noted that due to pilot revisions, results are not significant due to limited sample size.

The next step in the study is to conduct the full field experiment between Summer 2004 and Summer 2005. Upon completion, the study should yield approximately 150 students in 48 groups over four conditions with a statistical power of .5 assuming medium size effects. It is a known limitation of the study that effect size for the Blue and Orange conditions may vary due to how well each discourse group executes the process scaffold, in the absence of skilled process facilitators. However, the use of roles (i.e., facilitator, weaver, report writer) should minimize this variance and enable all groups to self-regulate.

\section{Contributions}

A major expected contribution of the study is building and testing a technology-mediated, discourse-centered, teaching and learning model called the ALN Cognitive Discourse Model. Since the study will not require special software, other than access to word processing and discussion board software, it will be widely accessible to teachers and students. Another contribution of the study is a comprehensive learning assessment strategy based on multidimensions of learning and multi-methods of assessment. Several adaptations were made in the study including Clark and Brennan [7] for TML, the Vee-Heuristic [29] for non-technical subjects, and Interactive Indicator [40] for presence of co-construction of knowledge.

\section{Acknowledgement}

This research is partially supported by grants from the New Jersey Commission on Science and Technology and the Alfred P. Sloan Foundation.

\section{References}

[1] Ausubel, David P., The Psychology of Meaningful Verbal Learning, Grune and Stratton, New York, 1963.

[2] Aviv, R., Erlich, A., Ravid, G., and Geva, A., "Network analysis of Knowledge Construction Asynchronous Learning Networks", Journal of Asynchronous Learning Networks 7(3), 2003. Available at: http://www.ravid.org/gilad/SAMOSICICTE.pdf 
[3] Baker, M., de Vries, E., Lund, K. and Quignard, M., "Computer-mediated epistemic interactions for co-constructing scientific notions: Lessons learned from a five-year research programme", Euro conference of Computer-Supported Collaborative Learning, Maastricht, the Netherlands, 2001. [4] Bloom, B.S. (Ed.), Taxonomy of Educational Objectives: Book I Cognitive Domain, Longman, New York, 1956.

[5] Clark, H.H. and Brennan S.E., "Grounding in Communication". In: Resnick, L.B., Levine, J., and Teasley, S.D. (Eds.) Perspectives on Socially Shared Cognition, American Psychological Association, Washington, 1991.

[6] Daft, R.L. and Lengel, R.H., "Organizational information requirements, media richness, and structural design", Management Science, 32, 5, 1986, pp. 554-571.

[7] de Vries, E., Lund, K. \& Baker, M., "Computermediated epistemic dialogue: Explanation and argumentation as vehicles for understanding scientific notions", Journal of the Learning Sciences, 11, 2002, pp. 63-103.

[8] Dennis, A. R., Valacich, J.S., "Rethinking media richness: Towards a theory of media synchronicity", HICSS32, 1999. Avail. at: http://www.computer.org/proceedings/hicss/0001/000 11/00011017 abs.htm?SMSESSION=NO

[9] Felder, R.M. and Soloman, B.A., Index of Learning Styles, $<$ http://www.ncsu.edu/felder-

public/ILSpage.html>, accessed 2/1/04.

[10] Frase, L.T., "Paragraph organization of written materials: The influence of conceptual clustering upon the level and organization of recall", Journal of Educational Psychology, 60, 1969, pp. 394-401.

[11] Gagne, R.M., The conditions of learning, 3rd ed., Holt, Rinehart, and Winston, New York, 1977.

[12] Gruber, H., \& Voneche, J. J. (Eds.), The essential Piaget (100th Anniversary Ed.), Jason Aronson, New York, 1995.

[13] Gunawardena, C., Lowe, C., and Anderson, T., "Analysis of global online debate and the development of an Interaction Analysis Model for examining social construction of knowledge in computer conferencing", Journal of Educational Computing Research, 17(4), 1997, pp. 397-431.

[14] Han,H.J., "Distributed Group Support

Systems:Group Decision Making Integrating Mobile Devices With Web-Based Group Communication", Unpublished Thesis. NJIT, 2003.

[15] Hara, N., Bonk, C., \& Angeli, C., "Content Analysis of Online Discussion in an AppliedEducational Psychology Course", Instructional Science, 28:2, 1998, pp. 115-152. [16] Hiltz, S.R. and Benbunan-Fich, R., "Supporting collaborative learning in asynchronous learning networks", Keynote address, UNESCO/Open University Symposium on Virtual Learning Environments and the Role of the Teacher, Milton Keynes, England, 1997.
[17] Hiltz, S.R., and Goldman, R.(Eds.), Learning Together Online: Research on Asynchronous Learning Networks. Erlbaum, Mahwah, New Jersey, 2004, in press.

[18] Holley, C.D., Dansereau, D.F., McDonald, B.A., Garland, J.C., and Collins, K.W., "Networking: The technique and the empirical evidence". In Holley, C.D. and Dansereau, D.F. (Eds.), Spatial Learning Strategies: Techniques, Applications and Related Issues, Academic Press, New York, 1997.

[19] Jeong, A.C., "The sequential analysis of group interaction and critical thinking in online threaded discussions", The American Journal of Distance Education, 17(1), 2003. Available at: http://www.ajde.com/Contents/vol17_1.htm. [20] Jonassen, D.H., "Using cognitive tools to represent problems", Journal of Research of Technology in Education, 35(30), 2003. Avail. at: http://www.iste.org/jrte/35/3/abstracts/ jonassen.cfm [21] Jones, B.F., Amiran, M.and Katims, M., "Teaching cognitive strategies and text structures within language arts programs". In Segal, J.W., Chipman, S.F. and Glaser, R. (Eds.), Thinking and Learning Skills, Lawrence Erlbaum, Hillsdale, NJ, 1985.

[22] Kakitalo, K., Hakkinen, P., Leinonen, P. and Jarvela, S., "Mechanisms of common ground in casebased web discussions in teacher education", Internet and Higher Education, 5, 2002. Avail. at: http://www.info.uta.fi/ttutk/ conference/makitalo.htm [23] Keen, G.W., "Information Systems and Organizational Change", Communications of the ACM, 24(1), 1981, pp.24 - 33.

[24] Kreijns, K., Kirschner, P.A. and Jochems, W., "Determining Sociability, Social Space, and Social Presence in (A)snchronous Collaborative Groups", Cyberpsychology \& Behavior, in press.

[25] Meyer, K. A., "Face-To-Face Versus Threaded Discussions: The Role of Time and Higher-Order Thinking", JALN, 7(3), 2003. Available at: http://www.aln.org/publications/jaln/ index.asp [26] Minsky, M., "A framework for representing knowledge". In Winston, P.H. (Ed.), The Psychology of Computer Vision, McGraw-Hill, New York, 1975. [27] Mowshowitz, A., "On Approaches to the Study of Social Issues in Computing”, Communications of the ACM, 24(3), 1981, pp.146-155.

[28] Novak, J.D., Learning, Creating and Using Knowledge, Erlbaum Associates, Mahway, New Jersey, 1998.

[29] Novak, J.D. and Gowin, D. G., Learning How to Learn, Cambridge University Press, Cambridge, 1984. [30] Nussbaum, E. Michael and Sinatra, G. M., "Argument and conceptual Engagement", Contemporary Educational Psychology, 28, 2003, pp. 384-395.

[31] O'Neil, H.F., Jr., \& Herl, H.E., "Reliability and validity of a trait measure of self-regulation", American Educational Research Association, San Diego, CA, 1998. 
[32] Pintrich, P. R., and Schunk, D. H., Motivation in Education: Theory, Research, and Applications, Prentice Hall, New York, 1995.

[33] Ravenscroft, A., "Designing argumentation for conceptual development", Computers and

Education,(34), 2000, pp. 241-255.

[34] Rewey, K.L., Dansereau, D.F., Skaggs, L.P., Hall, R.H., and Pitre, U., "Effects of scripted cooperation and knowledge maps on the processing of technical material", Journal of Educational Psychology, 81, 1989, pp. 604-609.

[35] Schmeck, Ribich \& Ramanaiah, Inventory of Learning Process ILP, 1997. Available at:

http://www-dsz.service.rug.nl/

bss/so/topics/research/gent2.htm

[36] Schwartz,S.H., "Modes of representation and problem solving: Well evolved is half solved", Journal of Experimental Psychology, 91, 1971, pp. 347-350.

[37] Shavelson, R.J., and Ruiz-Primo, M.A., "Windows into the Mind", Invited address, Facolta'di Ingegneria dell'Universita 'degli Studi di Ancona, June 27, 2000.

[38] Strijbos, J., Martens, R.L., Jochems, W. M. G., and Kirschner, P. A., "The effect of functional roles on perceived grup efficiency and communication during computer-supported collaborative learning", Annual Meeting of the American Educational

Research Association, San Diego, CA, 2004.

[39] Suthers, D. D., "Towards a Systematic Study of Representational Guidance for Collaborative learning Discourse", Journal of Universal Computer Science, 7(3), 2001. Avail. at:

http://ilt.ics.hawaii.edu/lilt/papers/ 2001/SuthersJUCS-01.pdf

[40] Swan, K., "Building learning communities in online courses: the importance of interaction",

Education, Communication \& Information, 2(1), 2002, pp. 23 - 49.

[41] Sweller, J., van Merrienboer, J.JG., and Paas, F., "Cognitive architecture and instructional design",

Educational Psychology review, 10, 1998, pp. 251296.

[42] Veerman, A.L., Andriessen, J.E.B. \& Kanselaar, G., "Collaborative learning through ComputerMediated Argumentation", 1999. Available: http://edu.fss.uu.nl/medewerkers/gk/files/Stanford_CS CL99.PDF

[43] Veerman, A. , "Constructive discussions through electronic dialogue". In Andriessen, J., Baker, M., and Suthers D. (Eds.), Arguing to Learn, Kluwer,

Netherlands, 2004.

[44] Vygotsky, L.S., Mind in society: The

development of higher

psychological processes, Harvard University Press, Cambridge, 1980.

[45] Walther, J.B., "Computer-mediated communication: Intrapersonal, interpersonal, and hyperpersonal interaction", Communication Research, 23, 1, 1996, pp. 3-43.

[46] White, B., "How can cognitive modelling, role playing and collaborative inquiry foster young learner's meta-socio-cognitive development?", Annual Meeting of the American Educational Research Association, San Diego, CA, 2004.

[47] Wong-Bushby, I., "Using Concept and Process Scaffolds to Support Collaborative Discourse in Asynchronous Learning Networks", Unpublished Thesis Proposal at NJIT, 2004. 